\title{
NLRP3 Inflammasome: The Stormy Link Between Obesity and COVID-19
}

\author{
Alberto López-Reyes ${ }^{1,2 *}$, Carlos Martinez-Armenta ${ }^{3}$, Rocio Espinosa-Velázquez ${ }^{2}$, \\ Paola Vázquez-Cárdenas ${ }^{4}$, Marlid Cruz-Ramos ${ }^{5}$, Berenice Palacios-Gonzalez ${ }^{6}$, \\ Luis Enrique Gomez-Quiroz ${ }^{7}$ and Gabriela Angélica Martínez-Nava ${ }^{8}$
}

${ }^{1}$ Laboratorio de Gerociencias, Instituto Nacional de Rehabilitación Luis Guillermo Ibarra Ibarra, Secretaría de Salud, Ciudad de México, México, 2 Facultad de Ciencias de la Salud, Universidad Anáhuac, Ciudad de México, México, ${ }^{3}$ Postgrado en Biología Experimental, Dirección de Ciencias Biológicas y de la Salud (DCBS), Universidad Autónoma Metropolitana Iztapalapa, Ciudad de México, México, ${ }^{4}$ Centro de Innovación Médica Aplicada, Hospital General Dr. Manuel Gea González, Ciudad de México, México, ${ }^{5}$ Cátedras de Consejo Nacional de Ciencia y Tecnología (CONACYT), Instituto Nacional de Cancerología, Ciudad de México, México, ${ }^{6}$ Unidad de Vinculación Científica de la Facultad de Medicina, Universidad Nacional Autónoma de México (UNAM), Instituto Nacional de Medicina Genómica, Ciudad de México, México, 7 Laboratorio de Fisiología Celular, Departamento de Ciencias de la Salud, Universidad Autónoma Metropolitana Iztapalapa, Ciudad de México, México, ${ }^{8}$ Laboratorio de Liquido Sinovial, Instituto Nacional de Rehabilitación Luis Guillermo Ibarra Ibarra, Ciudad de México, México

OPEN ACCESS

Edited by: Christophe Matthys, KU Leuven, Belgium

Reviewed by: Christopher Lupfer, Missouri State University, United States

Teneema Kuriakose St. Jude Children's Research Hospital, United States

*Correspondence: Alberto López-Reyes allorey@yahoo.com

Specialty section: This article was submitted to Nutritional Immunology, a section of the journal

Frontiers in Immunology

Received: 07 June 2020 Accepted: 13 October 2020 Published: 30 October 2020

Citation:

López-Reyes A, Martinez-Armenta C, Espinosa-Velázquez $R$, Vázquez-Cárdenas P, Cruz-Ramos M, Palacios-Gonzalez B, Gomez-Quiroz LE and Martínez-Nava GA (2020) NLRP3

Inflammasome: The Stormy Link Between Obesity and COVID-19.

Front. Immunol. 11:570251. doi: 10.3389/fimmu.2020.570251
Several countries around the world have faced an important obesity challenge for the past four decades as the result of an obesogenic environment. This disease has a multifactorial origin and it is associated with multiple comorbidities including type 2 diabetes, hypertension, osteoarthritis, metabolic syndrome, cancer, and dyslipidemia. With regard to dyslipidemia, hypertriglyceridemia is a well-known activator of the NLRP3 inflammasome, triggering adipokines and cytokines secretion which in addition induce a systemic inflammatory state that provides an adequate scenario for infections, particularly those mediated by viruses such as HIV, H1N1 influenza, and SARS-CoV-2. The SARS-CoV-2 infection causes the coronavirus disease 2019 (COVID-19) and it is responsible for the pandemic that we are currently living. COVID-19 causes an aggressive immune response known as cytokine release syndrome or cytokine storm that causes multiorgan failure and in most cases leads to death. In the present work, we aimed to review the molecular mechanisms by which obesity-associated systemic inflammation could cause a more severe clinical presentation of COVID-19. The SARS-CoV-2 infection could potentiate or accelerate the pre-existing systemic inflammatory state of individuals with obesity, via the NLRP3 inflammasome activation and the release of pro-inflammatory cytokines from cells trough Gasdermin-pores commonly found in cell death by pyroptosis.

Keywords: severe acute respiratory syndrome coronavirus 2, coronavirus disease 2019, pyroptosis, obesity, inflammasome

\section{INTRODUCTION}

Obesity has reached epidemic proportions globally; thus, the World Health Organization (WHO) identifies it as a serious public health problem, particularly in west countries (1). The global increase of obesity in the last 50 years has doubled, and it has been estimated that a third of the world population is obese or overweight (2). The WHO defines obesity as a complex entity in which there is an excessive 
accumulation of fat that affects practically all body functions and compromises the individual's health (1). Furthermore, obesity is considered the fifth risk factor for mortality, as it is the main risk factor of diabetes, cardiovascular disease, hypertension, dyslipidemia, musculoskeletal disorders such as osteoarthritis, and other diseases (3-5). It is well known that obesity leads to a low-grade chronic inflammation promoted by the release of adipokines and cytokines (6). This dysfunctional state contributes to a systemic lipotoxicity affecting liver, muscle and pancreas, activating NOD-, LRR-, and the pyrin domaincontaining protein 3 (NLRP3) inflammasome (7-10). Beyond cellular damage, organ dysfunction and metabolic compromise, the low-grade chronic inflammation could condition to viral diseases, such as those instigated by $\operatorname{HIV}(11,12), \mathrm{H} 1 \mathrm{~N} 1$ influenza virus (13-15), and SARS-CoV-2 (16).

The severe acute respiratory syndrome coronavirus 2 (SARS$\mathrm{CoV}-2$ ) causes the coronavirus disease (COVID-19), which is responsible for more than 758,942 deaths worldwide (17). The WHO has listed COVID-19 as a global health crisis (18). Similar to obesity, this virus induces a systemic inflammation; however, the SARS-CoV-2 produces an uncontrolled increase of cytokine secretion causing multiple organ failure, followed by death (1921). It should be noted that during the cytokine storm caused by SARS-CoV-2, the inflammasome could be involved in the maintenance of inflammation, as it happens in obesity (2224). Given that obesity might be associated with the development of aggressive clinical symptoms in COVID-19, we aimed to suggest the possible role of NLRP3 inflammasome as a link between obesity and the increased risk for a severe COVID19 outcome.

\section{INFLAMMASOME AND PYROPTOSIS}

The NLRP3 inflammasome is a multiprotein complex present in macrophages, dendritic cells and other non-immune cells. The activation of NLRP3 as the pivotal component of the innate immune system, plays a critical role in the host defense against bacteria, fungi and viruses among others; however, the NLRP3 is also associated with metabolic and inflammatory conditions such as gout, diabetes mellitus, insulin resistance, and obesity (25-28).

The inflammasome is coordinated by the NLRP3 sensor [Nucleotide-Binding Oligomerization Domain (NOD), Leucinrich repeat (LRR), Pyrin domain (PYD), adaptor protein ASC, as well as the effector protein caspase 1] $(29,30)$. In most cases, the activation of NLRP3 is regulated by pathogen-associated molecular patterns (PAMPs) and damage-associated molecular patterns (DAMPs) that are recognized by the Toll-like receptors $(29,31)$. The canonical activation of NLRP3 requires two independent signals; an initial priming signal and a second one to be fully activated (Figure 1).

The priming signal begins when PAMPs and other inflammatory mediators such as interleukin 1-beta (IL-1 $\beta$ ) and tumor necrosis factor-alpha (TNF- $\alpha$ ) bind to their respective receptors (Pattern Recognition Receptors, IL-1 $\beta R$,
TNF- $\alpha \mathrm{R})$. These receptors induce the activation of nuclear factor kappa-light-chain-enhancer of activated B cells (NF- $\kappa B$ ), which promotes the transcription of NF- $\kappa \mathrm{B}$-dependent genes such as NLRP3, pro-IL-1 $\beta$, and pro-interleukin-18 (IL-18) (31-33). NF- $\kappa \mathrm{B}$ also modulates the gene expression of interleukin-6 (IL-6), interleukin-8 (IL-8), interleukin-12 (IL-12), TNF- $\alpha$, and interferon-gamma inducible protein 10 (IP-10) (31, 34). These cytokines play a critical role in acute inflammation, as well as in promoting the synthesis of acute phase proteins that modify permeability and endothelial functions leading to the recruitment of other immune system cells. In particular, TNF- $\alpha$ and IL- 6 regulate transcription and transduction of IL-1 $\beta$ (34).

The second activation signal of NLRP3 could be initiated by several extracellular stimulus including those mediated by crystals of cholesterol, uric acid, asbestos and $\beta$ amyloid, which induce the release of ROS (reactive oxygen species), as well as lysosomal enzyme cathepsin $\mathrm{B}$ and $\mathrm{Ca}^{2+}$ caused by a destabilization and rupture of lysosome or endosome (35-37). The increase of cathepsin $\mathrm{B}$ and $\mathrm{Ca}^{2+}$ as well as aberrant ionic flux may trigger mitochondrial damage. Mitochondrial dysfunction occurs via an increase of mitochondrial ROS, oxidized mitochondrial DNA, cardiolipins and proteins that respond to viruses such as mitofusin-1 and -2 or mitochondrial antiviral signaling protein, promoting the oligomerization of $\operatorname{NLRP} 3(25,38)$. This assembly allows caspase- 1 to start the cleavage of pro-IL- $1 \beta$ and pro-IL-18 (Figure 1).

The final step of the NLRP3 inflammasome activation is the cleavage of Gasdermin D (GSDMD) by caspase-1, resulting in the release of GSDMD N-terminal fragments that are essential for pore formation on cell membranes (39). These pores lead to the release of cytosolic content causing unrestrained dissemination of inflammatory mediators including IL-1 $\beta$, IL-18, that induce cell death by pyroptosis contributing to host immune defense $(40,41)$.

\section{OBESITY, INFLAMMASOME, AND PYROPTOSIS}

As a functional organ, adipose tissue (AT) is the main endocrine and immunological tissue implicated in the pathophysiology of obesity and metabolic dysfunction $(42,43)$. AT has a complex and heterogeneous composition that includes endothelium, extracellular proteins matrix, stem cells, fibroblasts and immune cells, and adipocytes (43-46). There are three types of AT. White AT is the organ responsible for storing energy mainly in the form of triglycerides for energy demand periods. In contrast, brown AT is composed of rich mitochondria and multivacuolar smaller adipocytes that are positive for the expression of uncoupling protein-1, which is responsible for thermogenesis and generation of heat rather than ATP from the oxidation of fatty acids (47). Finally, the most recently AT identified, beige adipocyte tissue, resembles BAT morphology and function, it can differentiate from precursors found in WAT in response to stimuli as cold exposure $(48-50)$. 


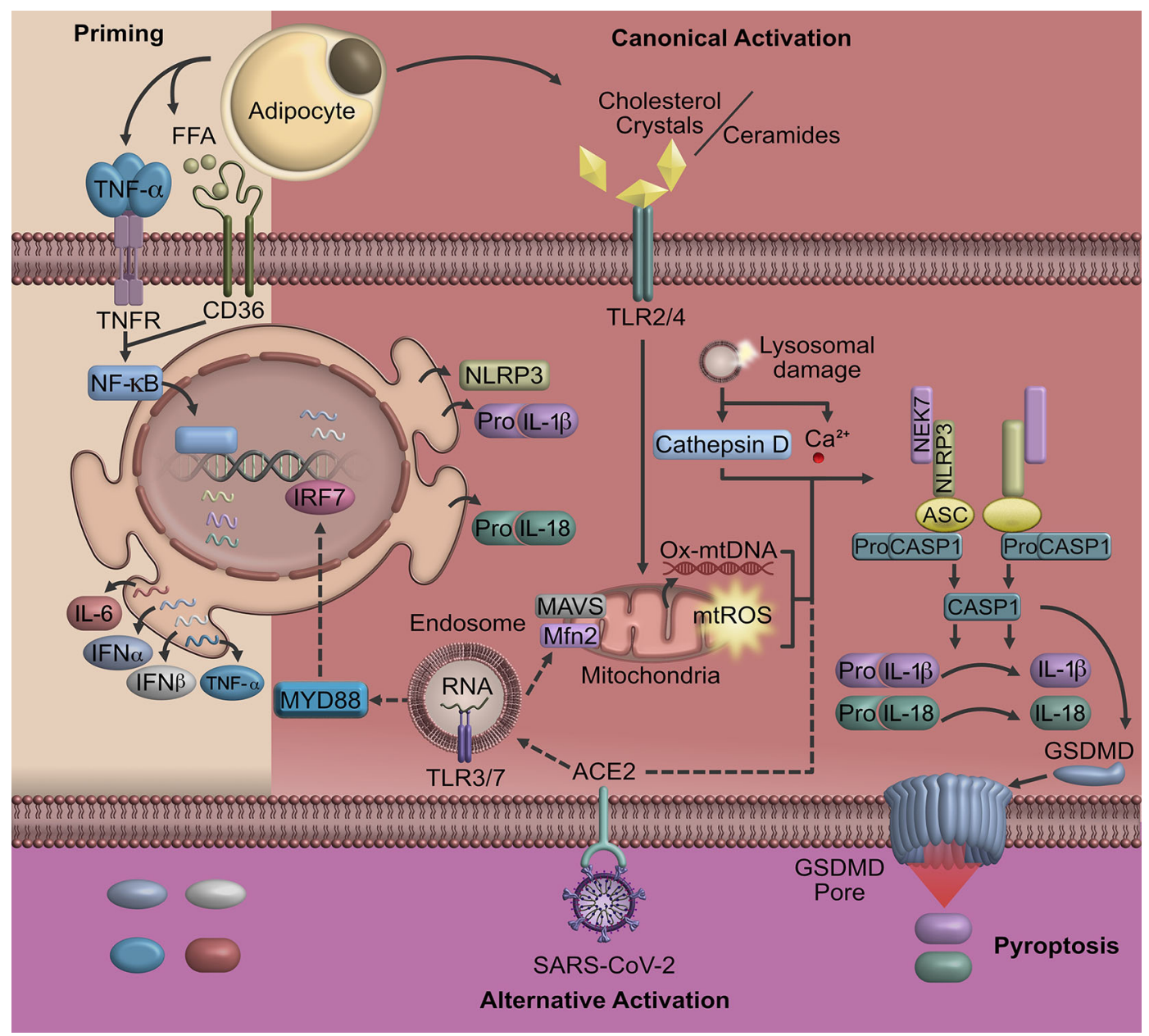

FIGURE 1 | Pyroptosis triggered in obesity and COVID-19. A possible signaling that triggers the activation of NLRP3 and consequently cell pyroptosis in COVID-19 may be linked to obesity. In individuals with obesity, pyroptosis is characterized by the activation of NOD-like receptors that induce the formation of cell membrane pores mediated by Gasdermin D and the release of inflammatory factors. The SARS-CoV-2 uses ACE2, a receptor highly express in AT, to entry human host cells promoting the expression of pro-inflammatory cytokines and oligomerization of NLRP3. Upon the NLRP3 inflammasome activation, Gasdermin-pores and cell membrane swelling promote cell pyroptosis, particularly in macrophages and lymphocytes. Cell signaling represented by straight lines show the canonical activation of NLRP3 in obesity. Dotted line represents the possible contribution of SARS-CoV-2 in NLRP3 activation. ACE2, angiotensin-converting enzyme 2; AT, adipose tissue; Mfn2, mitofusin-2; MAVS, mitochondrial antiviral signaling protein; GSDMD, Gasdermin D; IRF, interferon-regulatory factor; ROS, reactive oxygen species; TLR, toll-like receptor; SARS-CoV-2, severe acute respiratory syndrome coronavirus 2; TRIF, protein-inducing interferon- $\beta$.

In obesity, white AT promotes cellular, molecular and biochemical alterations that cause local and systemic changes. Locally, adipocyte hyperplasia and hypertrophy modify the AT structure; at a systemic level, these alterations promote inflammation, insulin resistance, nonalcoholic fatty liver diseases, and dyslipidemias $(42,45,51,52)$.

The impaired adipocytes function caused by hyperplasia and hypertrophy induce an exacerbated lipolysis releasing fatty acids (such as palmitic and lauric acids), and triggers the formation of ceramides and cholesterol crystals that activate tissue-resident macrophages through the TLR4 signaling (53-55). This macrophage stimulation itself triggers the production of ROS, calcium accumulation, as well as the release of IL-6, TNF- $\alpha$, and monocyte chemoattractant protein-1 (MCP-1) (56-58). The chemokine MCP-1 leads to the recruitment of monocytes, while the interferon gamma (IFN- $\gamma$ ), secreted by T cells in AT stimulates a polarization process in macrophages, from the anti-inflammatory state (M2) to the pro-inflammatory (M1) phenotype thereby perpetuating a low-grade systemic inflammation $(56,57,59,60)$.

The inflammatory activity of M1 macrophages is traditionally mediated by the activation of TNF- $\alpha$ R, IL- $1 \beta R$, and CD36, which is a priming signaling that activates NF- $\mathrm{KB}$ promoting the transcription of NLRP3, pro-IL-1 $\beta$, pro-IL-18, and other inflammatory cytokines (61). However, for the NLRP3 inflammasome assembly, a second hit is required; this second hit is induced by the binding of ceramides, fatty acids, oxidized low-density lipoproteins and cholesterol crystals to TLR 2/4 (37, $58,62-64)$. Finally, the sustained activation of NLRP3 will induce the assembly of GSDMD pores into the macrophage cell 
membrane $(40,65)$. This process constitutes the pyroptotic cell death mechanism, disrupting the osmotic potential and pouring pro-inflammatory molecules to the system (65) (Figure 1).

\section{COVID-19, INFLAMMASOME, AND PYROPTOSIS}

The causal agent of COVID-19 is known as SARS-CoV-2. The viral infection is mediated by the attachment between a spike glycoprotein and the angiotensin-converting enzyme 2 (ACE2) in human host cells (66). The host target receptor mediates a virus-cell membrane fusion and a viral entry that could cause virus-linked pyroptosis $(67,68)$, leading to SARS-CoV-2induced lymphopenia $(22,69)$.

The innate immune system cells detect the viral RNA by Pattern Recognition Receptors like TLR 3/7 in the endosome; then, cascades of signaling pathways are triggered by TRIF and MyD88 leading to the activation of transcription factors including NF- $\mathrm{KB}$ and interferon-regulatory factor $3 / 7$ (IRF) (70). Not only TLR signaling can induce an excessive inflammatory response to SARS-CoV-2, the inflammasome activation stimulated by viral internalization can also induce it; presumably, this occurs through spike proteins binding to CD147 (71). The massive release of TNF- $\alpha$, IFN- $\gamma$, IL- $1 \beta$, IL- 8 , MCP-1, and IP-10 seen in acute phase of COVID-19 patients (22) may probably be linked to pyroptosis, especially in lymphocytes through the NLRP3 inflammasome activation.

The pyroptosis-mediated cell death has been described previously in another coronavirus infection $(72,73)$. Recent evidence suggests that Severe Acute Respiratory Syndrome-related Coronavirus (SARS-CoV) induces NLRP3-dependent pyroptosis in macrophages, which is triggered by the essential ion channel activity of viroporin $3 \mathrm{a}$ (72) as well as by a direct interaction of ORF8b with the LRR domain of NLRP3 (73). Moreover, it has been demonstrated that ORF3a and E protein can stimulate NF- $\mathrm{KB}$ signaling, resulting in the transcription of NLRP3, chemokines, and pro-inflammatory cytokine, including IL-1 $\beta$, IL-18, and IL-8 (74-76). Additionally, ORF3a might also mediate NLRP3 inflammasome activation through the ubiquitination of ASC promoting maturation and secretion of IL-1 $\beta$ (75). In contrast, E protein induces the assembly of NLRP3 inflammasome via the formation of pores in Endoplasmic Reticulum-Golgi intermediate compartment membranes that triggers a massive calcium ion transportation to the cytosol (77-79). Finally, Chang et al. highlight the biological role of SARS-CoV unique domain (SUD) as a direct inductor of NLRP3 inflammasome activation in alveolar epithelial cells, as well as its activity modulating pulmonary inflammation mediated by CXCL10 in vitro and in vivo through NLRP3 inflammasome pathway (80). These molecular mechanisms have been linked to the induction of cytokine storm and cell death in SARS-CoV $(72,73,81,82)$.

In the particular case of SARS-CoV-2 strains, recent evidence suggests similar signaling pathways with SARS-CoV in modulating the inflammation by activating NLRP3. A novel study has revealed homology functional domains of ORF3a when compared with those reported in SARS-CoV strains, suggesting some hypothetical pathways of ORF3a linked to the NF- $\mathrm{KB}$ activation and NLRP3 inflammasome assembly (83). Considering SARS-CoV-2 has high nucleotide sequence homology to SARS-CoV and $94.7 \%$ amino acid identity of $\mathrm{E}$ protein $(84,85)$, it could be inferred that pyroptosis might play a central role in the pathogenesis of COVID-19. Individuals infected with SARS-CoV-2 often show high concentration of proinflammatory cytokines $(22,86)$, which is a downstream indicator of inflammatory programmed cell death (Figure 1) (65).

Different reports have shown that COVID-19 is characterized by a dysfunctional immune response, which exacerbates the disease progression as result of a persistent inflammation associated with high peripheral levels of IL-1 $\beta$, IL-6, TNF- $\alpha$, MCP-1, and IP10 (22, 87-89). This aggravated inflammatory response triggers a cytokine storm, contributing to the pathological inflammation and multi-organ injury seen in severely ill COVID-19 patients $(23,90-92)$. With regard to the exacerbated inflammation probably caused by aberrant activation of NLRP3 inflammasome in COVID-19, potential targets are being explored including host signaling proteins and effector molecules that lead cytokine storm (24, 93-95).

To date, some different drugs such as Acalabrutinib have shown their beneficial effects in COVID-19. This therapeutic strategy inhibits the Bruton tyrosine kinase (BTK) enzyme, which is a direct regulator in NLRP3 inflammasome activation $(96,97)$. The use of the drug in severe COVID-19 patients showed a decrease in serum inflammatory biomarkers (24). Furthermore, Colchicine (93-95) has been successfully tested as inhibitor of NLRP3 inflammasome, improving survival outcomes in COVID19 patients since it suppresses caspase- 1 activation and subsequent IL- $1 \beta$ and IL-18 processing $(94,98)$. In this sense, Hydroxychloroquine, another NLRP3 inhibitor, has shown a role affecting the NLRP3 inflammasome activation and assembly (99-101). In addition, different clinical trials registered to evaluate the efficacy of pharmacological inhibitors of the NLRP3 inflammasome in treating COVID-19; include Colchicine (NCT04326790, NCT04322565, NCT04328480, NCT04322682), Hydroxychloroquine in combination with Azithromycin (NCT04339816, NCT04336332), Melatonin (NCT04409522), and Tranilast (ChiCTR2000030002); versus standard care.

In other hand, recent studies have evaluated the use of Anakinra $(102,103)$ as a therapeutic strategy focused in signaling inhibition of IL- $1 \beta$ to treat COVID-19 related cytokine storm. This drug is a human IL- $1 \beta$ receptor antagonist that inhibits inflammation response. Moreover, there are different clinical trials registered to study the efficacy and safety of Canakinumab (anti-IL-1 $\beta$ monoclonal antibody) in COVID-19induce pneumonia (NCT04362813, NCT04348448) and COVID19 cardiac injury (NCT04365153). In addition, Tocilizumab (antiIL-6 treatment) showed clinical improvement in COVID-19 patients (104-106). There are few drugs with mechanisms of action targeting NLRP3 such as Necrosulfonamide (107) and Disulfiram (108), by inhibiting the N-terminal GSDMD pores. The NLRP3 inhibition may represent an optimal strategy to 
mitigate the impact of comorbidities associated with COVID-19 such as diabetes mellitus (109, 110), hypertension (111), and obesity $(112,113)$.

\section{THE CLINICAL IMPACT OF OBESITY IN COVID-19}

Different studies have reported fatal COVID-19 outcomes in individuals with at least one chronic disease such as hypertension, diabetes, cardiovascular disease, and obesity $(87,114-116)$. In individuals infected with SARS-CoV-2, overweight and obesity could be conditioning the critical outcome of COVID-19. The high number of young individuals with COVID-19 that have been hospitalized might be explained by the high obesity incidence found among them (117-119). Furthermore, data suggest that overweight and obesity determined by BMI are associated with the presence of severe pneumonia or increased incidence of ICU admission of individuals with COVID-19 in the USA (117, 120, 121), China (122, 123), Mexico (114, 124), and France (125).

A possible explanation is that tissue expression of ACE2 may play a key role in the progression of COVID-19 patients with obesity, since obese individuals have increased AT mass that leads to an elevated number of ACE2-expressing cells and therefore an increased risk of SARS-CoV-2 infection $(126,127)$. Other obesityimplicated conditions have been associated with a severe course of COVID-19 such as respiratory symptoms, impaired metabolic health, cardiac stress, dysfunctional host defense against viral infection, and multi-organ damage (120, 125).

Interestingly, obesity has been associated with a decrease in mortality in patients with acute respiratory distress syndrome (ARDS), and this is referred to as the "obesity paradox". However, the high mortality among patients with obesity who manifest SARSCoV-2 infection has prompted the notion that SARS-CoV-2 has disproved the "obesity paradox" in ARDS $(128,129)$. The paradox fades if body composition (i.e., fat mass, lean mass, and skeletal muscle mass), body fat distribution (abdominal obesity carries a higher risk of developing metabolic disorders than peripheral or gluteofemoral obesity), AT functionality, and the differences between subcutaneous and visceral AT are considered (130-135). Moreover, the metabolically unhealthy obese phenotype seems to be associated with increased activation of the NLPR3 in macrophages infiltrating visceral AT and a less favorable inflammatory profile than the metabolically healthy phenotype (136). In obese individuals, the innate immune system might be already in a "primed state" due to chronic low-grade inflammation and this could promote an hyperinflammatory response $(137,138)$; under this scenario, we wonder if trained immunity mediated by NLRP3 in obese conditions to severe outcomes in COVID-19 patients, or normal weight patients infected by SARS-CoV-2 are developing trained immunity that accelerates and trigger short-term development of degenerative chronic comorbidities such as atherosclerosis, diabetes, osteoarthritis, gout, autoimmune diseases, and even obesity itself. This sustained activation state could induce poor clinical outcomes of COVID-19, amplifying the pro-inflammatory response to SARSCoV-2 infection (Figure 2).

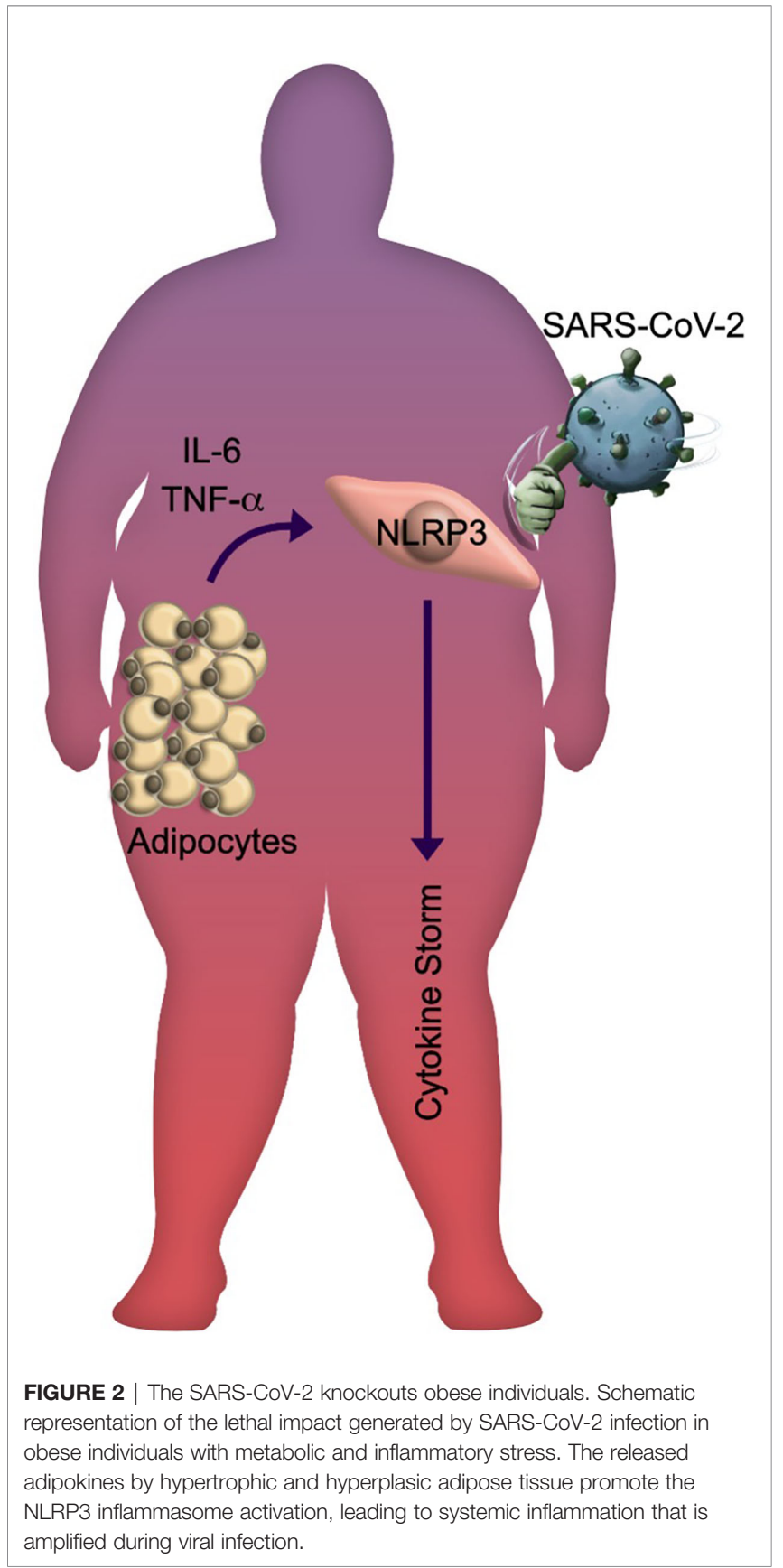

\section{DISCUSSION}

Recent evidence suggests that 1) AT hypertrophy and hyperplasia promote the synthesis of triglycerides, oxidized phospholipids, IL-1 $\beta$, TNF- $\alpha$, and adipokines triggering the systemic inflammatory state regularly observed in individuals with obesity $(53-55) ; 2$ ) these molecules are responsible for increasing the vulnerability to infections in individuals with obesity because the priming phase of the inflammasome is already active (61); 3) the recognition of SARS-CoV-2 by endosomal TLRs $3 / 7$ will trigger multiple signaling and cellular pathways that will allow inflammasome assembly and 
consequent maturation of cytosolic pro-cytokines such as IL-1 $\beta$ and IL-18 as well as the activation of $\operatorname{GSDMD}(70,83) ; 4)$ the Gasdermin-pore formation will start cell death by pyroptosis via the release of pro-inflammatory mediators in COVID-19 patients $(22,83,86)$. To summarize the recognition of the molecular pathways involved in the inflammasome might explain the vulnerability of obese patients to develop severe cases of COVID-19 (Figure 2).

\section{AUTHOR CONTRIBUTIONS}

AL-R developed the concept for the review. MC-R, CM-A, and RE-V wrote the manuscript. PV-C, LG-Q, BP-G, and GN

\section{REFERENCES}

1. World Health Organization. Obesity and overweight (2020). Available at: http://www.who.int/en/news-room/fact-sheets/detail/obesity-andoverweight (Accessed July 2, 2020).

2. Chooi YC, Ding C, Magkos F. The epidemiology of obesity. Metabolism (2019) 92:6-10. doi: 10.1016/j.metabol.2018.09.005

3. Koliaki C, Liatis S, Kokkinos A. Obesity and cardiovascular disease: revisiting an old relationship. Metabolism (2019) 92:98-107. doi: 10.1016/ j.metabol.2018.10.011

4. Medina-Luna D, Santamaria-Olmedo MG, Zamudio-Cuevas Y, MartinezFlores K, Fernandez-Torres J, Martinez-Nava GA, et al. Hyperlipidemic microenvironment conditionates damage mechanisms in human chondrocytes by oxidative stress. Lipids Health Dis (2017) 16(1):114. doi: 10.1186/s12944-017-0510-x

5. Piche ME, Tchernof A, Despres JP. Obesity Phenotypes, Diabetes, and Cardiovascular Diseases. Circ Res (2020) 126(11):1477-500. doi: 10.1161/ CIRCRESAHA.120.316101

6. Unamuno X, Gomez-Ambrosi J, Rodriguez A, Becerril S, Fruhbeck G, Catalan V. Adipokine dysregulation and adipose tissue inflammation in human obesity. Eur J Clin Invest (2018) 48(9):e12997. doi: 10.1111/eci.12997

7. Rheinheimer J, de Souza BM, Cardoso NS, Bauer AC, Crispim D. Current role of the NLRP3 inflammasome on obesity and insulin resistance: A systematic review. Metabolism (2017) 74:1-9. doi: 10.1016/j.metabol. 2017.06.002

8. Farrell GC, Haczeyni F, Chitturi S. Pathogenesis of NASH: How Metabolic Complications of Overnutrition Favour Lipotoxicity and Pro-Inflammatory Fatty Liver Disease. Adv Exp Med Biol (2018) 1061:19-44. doi: 10.1007/978981-10-8684-7_3

9. Oh YS, Bae GD, Baek DJ, Park EY, Jun HS. Fatty Acid-Induced Lipotoxicity in Pancreatic Beta-Cells During Development of Type 2 Diabetes. Front Endocrinol (Lausanne) (2018) 9:384. doi: 10.3389/fendo.2018.00384

10. Barra NG, Henriksbo BD, Anhe FF, Schertzer JD. The NLRP3 inflammasome regulates adipose tissue metabolism. Biochem J (2020) 477 (6):1089-107. doi: 10.1042/BCJ20190472

11. Srinivasa S, Fitch KV, Torriani M, Zanni MV, Defilippi C, Christenson R, et al. Relationship of visceral and subcutaneous adipose depots to markers of arterial injury and inflammation among individuals with HIV. AIDS (2019) 33(2):229-36. doi: 10.1097/QAD.0000000000002060

12. Damouche A, Lazure T, Avettand-Fenoel V, Huot N, Dejucq-Rainsford N, Satie AP, et al. Adipose Tissue Is a Neglected Viral Reservoir and an Inflammatory Site during Chronic HIV and SIV Infection. PLoS Pathog (2015) 11(9):e1005153. doi: 10.1371/journal.ppat.1005153

13. Sun Y, Wang Q, Yang G, Lin C, Zhang Y, Yang P. Weight and prognosis for influenza A(H1N1)pdm09 infection during the pandemic period between 2009 and 2011: a systematic review of observational studies with meta-analysis. Infect Dis (Lond) (2016) 48(11-12):813-22. doi: 10.1080/23744235.2016.1201721

14. Zhou Y, Cowling BJ, Wu P, Chan WM, Lee SY, Lau EH, et al. Adiposity and influenza-associated respiratory mortality: a cohort study. Clin Infect Dis (2015) 60(10):e49-57. doi: 10.1093/cid/civ060 contributed to the editing and contextual design. All authors contributed to the article and approved the submitted version.

\section{FUNDING}

Financial support: CONACYT 312513 SARS-COV 2.

\section{ACKNOWLEDGMENTS}

We gratefully thank the extraordinary effort of healthcare workers who take care of individuals infected with SARS-CoV-2.

15. Neidich SD, Green WD, Rebeles J, Karlsson EA, Schultz-Cherry S, Noah TL, et al. Increased risk of influenza among vaccinated adults who are obese. Int J Obes (Lond) (2017) 41(9):1324-30. doi: 10.1038/ijo.2017.131

16. Chiappetta S, Sharma AM, Bottino V, Stier C. COVID-19 and the role of chronic inflammation in patients withobesity. Int J Obes (Lond) (2020) 44:1790-2. doi: 10.1038/s41366-020-0597-4

17. Worldmeters. COVID-19 Coronavirus Pandemic (2020). Available at: https://www.worldometers.info/coronavirus/ (Accessed August 14, 2020).

18. World Health Organization. Coronavirus disease 2019 (COVID-19) pandemic (2020). Available at: https://www.who.int/emergencies/diseases/ novel-coronavirus-2019 (Accessed July 2, 2020).

19. Wu C, Chen X, Cai Y, Xia J, Zhou X, Xu S, et al. Risk Factors Associated With Acute Respiratory Distress Syndrome andDeath in Patients With Coronavirus Disease 2019 Pneumonia in Wuhan, China. JAMA Intern Med (2020) 180(7):934-43. doi: 10.1001/jamainternmed.2020.0994

20. Xu Z, Shi L, Wang Y, Zhang J, Huang L, Zhang C, et al. Pathological findings of COVID-19 associated with acute respiratory distress syndrome. Lancet Respir Med (2020) 8(4):420-2. doi: 10.1016/S2213-2600(20)30076-X

21. Mehta P, McAuley DF, Brown M, Sanchez E, Tattersall RS, Manson JJ, et al. COVID-19: consider cytokine storm syndromes and immunosuppression. Lancet (2020) 395(10229):1033-4. doi: 10.1016/S0140-6736(20)30628-0

22. Huang C, Wang Y, Li X, Ren L, Zhao J, Hu Y, et al. Clinical features of patients infected with 2019 novel coronavirus in Wuhan, China. Lancet (2020) 395(10223):497-506. doi: 10.1016/S0140-6736(20)30183-5

23. Chen G, Wu D, Guo W, Cao Y, Huang D, Wang H, et al. Clinical and immunological features of severe and moderate coronavirus disease 2019. J Clin Invest (2020) 130(5):2620-9. doi: 10.1172/JCI137244

24. Roschewski M, Lionakis MS, Sharman JP, Roswarski J, Goy A, Monticelli $\mathrm{MA}$, et al. Inhibition of Bruton tyrosine kinase in patients with severeCOVID-19. Sci Immunol (2020) 5(48):eabd0110. doi: 10.1126/ sciimmunol.abd0110

25. Gurung P, Lukens JR, Kanneganti TD. Mitochondria: diversity in the regulation of the NLRP3 inflammasome. Trends Mol Med (2015) 21 (3):193-201. doi: 10.1016/j.molmed.2014.11.008

26. Liu H, Xu R, Kong Q, Liu J, Yu Z, Zhao C. Downregulated NLRP3 and NLRP1 inflammasomes signaling pathways in the development and progression of type 1 diabetes mellitus. BioMed Pharmacother (2017) 94:619-26. doi: 10.1016/j.biopha.2017.07.102

27. Wan X, Xu C, Lin Y, Lu C, Li D, Sang J, et al. Uric acid regulates hepatic steatosis and insulin resistance through the NLRP3 inflammasomedependent mechanism. J Hepatol (2016) 64(4):925-32. doi: 10.1016/ j.jhep.2015.11.022

28. Sun X, Hao H, Han Q, Song X, Liu J, Dong L, et al. Human umbilical cordderived mesenchymal stem cells ameliorate insulin resistance by suppressing NLRP3 inflammasome-mediated inflammation in type 2 diabetes rats. Stem Cell Res Ther (2017) 8(1):241. doi: 10.1186/s13287-017-0668-1

29. Clavijo-Cornejo D, Martinez-Flores K, Silva-Luna K, Martinez-Nava GA, Fernandez-Torres J, Zamudio-Cuevas Y, et al. The Overexpression of NALP3 Inflammasome in Knee Osteoarthritis Is Associated with Synovial 
Membrane Prolidase and NADPH Oxidase 2. Oxid Med Cell Longev (2016) 2016:1472567. doi: 10.1155/2016/1472567

30. Guey B, Bodnar M, Manie SN, Tardivel A, Petrilli V. Caspase-1 autoproteolysis is differentially required for NLRP1b and NLRP3 inflammasome function. Proc Natl Acad Sci U S A (2014) 111(48):17254-9. doi: 10.1073/pnas.1415756111

31. Swanson KV, Deng M, Ting JP. The NLRP3 inflammasome: molecular activation and regulation to therapeutics. Nat Rev Immunol (2019) 19 (8):477-89. doi: 10.1038/s41577-019-0165-0

32. Ketelut-Carneiro N, Silva GK, Rocha FA, Milanezi CM, Cavalcanti-Neto FF, Zamboni DS, et al. IL-18 triggered by the Nlrp3 inflammasome induces host innate resistance in a pulmonary model of fungal infection. I Immunol (2015) 194(9):4507-17. doi: 10.4049/jimmunol.1402321

33. Zhao X, Zhang C, Hua M, Wang R, Zhong C, Yu J, et al. NLRP3 inflammasome activation plays a carcinogenic role through effector cytokine IL-18 in lymphoma. Oncotarget (2017) 8(65):108571-83. doi: 10.18632/oncotarget.21010

34. Boriushkin E, Wang JJ, Li J, Bhatta M, Zhang SX. p58(IPK) suppresses NLRP3 inflammasome activation and IL-1beta production via inhibition of PKR in macrophages. Sci Rep (2016) 6:25013. doi: 10.1038/srep25013

35. Thompson JK, MacPherson MB, Beuschel SL, Shukla A. Asbestos-Induced Mesothelial to Fibroblastic Transition Is Modulated by the Inflammasome. Am J Pathol (2017) 187(3):665-78. doi: 10.1016/j.ajpath.2016.11.008

36. Zheng SC, Zhu XX, Xue Y, Zhang LH, Zou HJ, Qiu JH, et al. Role of the NLRP3 inflammasome in the transient release of IL-1beta induced by monosodium urate crystals in human fibroblast-like synoviocytes. J Inflammation (Lond) (2015) 12:30. doi: 10.1186/s12950-015-0070-7

37. Rajamaki K, Lappalainen J, Oorni K, Valimaki E, Matikainen S, Kovanen PT, et al. Cholesterol crystals activate the NLRP3 inflammasome in human macrophages: a novel link between cholesterol metabolism and inflammation. PLoS One (2010) 5(7):el1765. doi: 10.1371/journal.pone.0011765

38. Zhao C, Zhao W. NLRP3 Inflammasome-A Key Player in Antiviral Responses. Front Immunol (2020) 11:211. doi: 10.3389/fimmu.2020.00211

39. He WT, Wan H, Hu L, Chen P, Wang X, Huang Z, et al. Gasdermin D is an executor of pyroptosis and required for interleukin-1beta secretion. Cell Res (2015) 25(12):1285-98. doi: 10.1038/cr.2015.139

40. Liu X, Zhang Z, Ruan J, Pan Y, Magupalli VG, Wu H, et al. Inflammasomeactivated gasdermin $\mathrm{D}$ causes pyroptosis by forming membrane pores. Nature (2016) 535(7610):153-8. doi: 10.1038/nature18629

41. He Y, Hara H, Nunez G. Mechanism and Regulation of NLRP3 Inflammasome Activation. Trends Biochem Sci (2016) 41(12):1012-21. doi: 10.1016/j.tibs.2016.09.002

42. Caer C, Rouault C, Le Roy T, Poitou C, Aron-Wisnewsky J, Torcivia A, et al. Immune cell-derived cytokines contribute to obesity-related inflammation, fibrogenesis and metabolic deregulation in human adipose tissue. Sci Rep (2017) 7(1):3000. doi: 10.1038/s41598-017-02660-w

43. McLaughlin T, Liu LF, Lamendola C, Shen L, Morton J, Rivas H, et al. T-cell profile in adipose tissue is associated with insulin resistance and systemic inflammation in humans. Arterioscler Thromb Vasc Biol (2014) 34 (12):2637-43. doi: 10.1161/ATVBAHA.114.304636

44. Mohiuddin OA, Campbell B, Poche JN, Thomas-Porch C, Hayes DA, Bunnell BA, et al. Decellularized Adipose Tissue: Biochemical Composition, in vivo Analysis and Potential Clinical Applications. Adv Exp Med Biol (2020) 1212:57-70. doi: 10.1007/5584_2019_371

45. Hoffstedt J, Arner E, Wahrenberg H, Andersson DP, Qvisth V, Lofgren P, et al. Regional impact of adipose tissue morphology on the metabolic profile in morbid obesity. Diabetologia (2010) 53(12):2496-503. doi: 10.1007/ s00125-010-1889-3

46. Zhang C, Wang JJ, He X, Wang C, Zhang B, Xu J, et al. Characterization and Beige Adipogenic Potential of Human Embryo White Adipose Tissue-Derived Stem Cells. Cell Physiol Biochem (2018) 51(6):2900-15. doi: 10.1159/000496042

47. Choe SS, Huh JY, Hwang IJ, Kim JI, Kim JB. Adipose Tissue Remodeling: Its Role in Energy Metabolism and Metabolic Disorders. Front Endocrinol (Lausanne) (2016) 7:30. doi: 10.3389/fendo.2016.00030

48. Garcia-Ruiz E, Reynes B, Diaz-Rua R, Ceresi E, Oliver P, Palou A. The intake of high-fat diets induces the acquisition of brown adipocyte gene expression features in white adipose tissue. Int J Obes (Lond) (2015) 39(11):1619-29. doi: $10.1038 /$ ijo.2015.112

49. Saito M, Okamatsu-Ogura Y, Matsushita M, Watanabe K, Yoneshiro T, NioKobayashi J, et al. High incidence of metabolically active brown adipose tissue in healthy adult humans: effects of cold exposure and adiposity. Diabetes (2009) 58(7):1526-31. doi: 10.2337/db09-0530

50. Xu Z, You W, Zhou Y, Chen W, Wang Y, Shan T. Cold-induced lipid dynamics and transcriptional programs in white adipose tissue. BMC Biol (2019) 17(1):74. doi: 10.1186/s12915-019-0693-x

51. Belligoli A, Compagnin C, Sanna M, Favaretto F, Fabris R, Busetto L, et al. Characterization of subcutaneous and omental adipose tissue in patients with obesity and with different degrees of glucose impairment. Sci Rep (2019) 9(1):11333. doi: 10.1038/s41598-019-47719-y

52. Mulder P, Morrison MC, Verschuren L, Liang W, van Bockel JH, Kooistra T, et al. Reduction of obesity-associated white adipose tissue inflammation by rosiglitazone is associated with reduced non-alcoholic fatty liver disease in LDLr-deficient mice. Sci Rep (2016) 6:31542. doi: 10.1038/srep31542

53. Lee JY, Sohn KH, Rhee SH, Hwang D. Saturated fatty acids, but not unsaturated fatty acids, induce the expression of cyclooxygenase- 2 mediated through Toll-like receptor 4. J Biol Chem (2001) 276(20):166839. doi: 10.1074/jbc.M011695200

54. Lee JY, Ye J, Gao Z, Youn HS, Lee WH, Zhao L, et al. Reciprocal modulation of Toll-like receptor-4 signaling pathways involving MyD88 and phosphatidylinositol 3-kinase/AKT by saturated and polyunsaturated fatty acids. J Biol Chem (2003) 278(39):37041-51. doi: 10.1074/jbc.M305213200

55. Giordano A, Murano I, Mondini E, Perugini J, Smorlesi A, Severi I, et al. Obese adipocytes show ultrastructural features of stressed cells and die of pyroptosis. J Lipid Res (2013) 54(9):2423-36. doi: 10.1194/jlr.M038638

56. Fujisaka S, Usui I, Ikutani M, Aminuddin A, Takikawa A, Tsuneyama K, et al. Adipose tissue hypoxia induces inflammatory M1 polarity of macrophages in an HIF-1alpha-dependent and HIF-1alpha-independent manner in obese mice. Diabetologia (2013) 56(6):1403-12. doi: 10.1007/ s00125-013-2885-1

57. Nishimura S, Manabe I, Nagasaki M, Eto K, Yamashita H, Ohsugi M, et al. $\mathrm{CD} 8+$ effector $\mathrm{T}$ cells contribute to macrophage recruitment and adipose tissue inflammation in obesity. Nat Med (2009) 15(8):914-20. doi: 10.1038/ nm.1964

58. Okla M, Zaher W, Alfayez M, Chung S. Inhibitory Effects of Toll-Like Receptor 4, NLRP3 Inflammasome, and Interleukin-1beta on White Adipocyte Browning. Inflammation (2018) 41(2):626-42. doi: 10.1007/ s10753-017-0718-y

59. Lumeng CN, Bodzin JL, Saltiel AR. Obesity induces a phenotypic switch in adipose tissue macrophage polarization. J Clin Invest (2007) 117(1):175-84. doi: $10.1172 / J C I 29881$

60. Kanda H, Tateya S, Tamori Y, Kotani K, Hiasa K, Kitazawa R, et al. MCP-1 contributes to macrophage infiltration into adipose tissue, insulin resistance, and hepatic steatosis in obesity. J Clin Invest (2006) 116(6):1494-505. doi: 10.1172/JCI26498

61. Russo L, Lumeng CN. Properties and functions of adipose tissue macrophages in obesity. Immunology (2018) 155(4):407-17. doi: 10.1111/ imm. 13002

62. Karasawa T, Kawashima A, Usui-Kawanishi F, Watanabe S, Kimura H, Kamata R, et al. Saturated Fatty Acids Undergo Intracellular Crystallization and Activate the NLRP3 Inflammasome in Macrophages. Arterioscler Thromb Vasc Biol (2018) 38(4):744-56. doi: 10.1161/ATVBAHA.117.310581

63. Wen H, Gris D, Lei Y, Jha S, Zhang L, Huang MT, et al. Fatty acid-induced NLRP3-ASC inflammasome activation interferes with insulin signaling. Nat Immunol (2011) 12(5):408-15. doi: 10.1038/ni.2022

64. Camell CD, Nguyen KY, Jurczak MJ, Christian BE, Shulman GI, Shadel GS, et al. Macrophage-specific de Novo Synthesis of Ceramide Is Dispensable for Inflammasome-driven Inflammation and Insulin Resistance in Obesity. J Biol Chem (2015) 290(49):29402-13. doi: 10.1074/jbc.M115.680199

65. Evavold CL, Ruan J, Tan Y, Xia S, Wu H, Kagan JC. The Pore-Forming Protein Gasdermin D Regulates Interleukin-1 Secretion from Living Macrophages. Immunity (2018) 48(1):35-44e6. doi: 10.1016/j.immuni.2017.11.013

66. Zhou P, Yang XL, Wang XG, Hu B, Zhang L, Zhang W, et al. A pneumonia outbreak associated with a new coronavirus of probable bat origin. Nature (2020) 579(7798):270-3. doi: 10.1038/s41586-020-2012-7

67. Yang M. Cell pyroptosis, a potential pathogenic mechanism of 2019-nCoV infection. SSRN (2020). doi: 10.2139/ssrn.3527420

68. Yang Y, Peng F, Wang R, Yange M, Guan K, Jiang T, et al. The deadly coronaviruses: The 2003 SARS pandemic and the 2020 novel coronavirus 
epidemic in China. J Autoimmun (2020) 109:102434. doi: 10.1016/ j.jaut.2020.102434

69. Guan WJ, Ni ZY, Hu Y, Liang WH, Ou CQ, He JX, et al. Clinical Characteristics of Coronavirus Disease 2019 in China. N Engl J Med (2020) 382(18):1708-20. doi: 10.1056/NEJMoa2002032

70. Li G, Fan Y, Lai Y, Han T, Li Z, Zhou P, et al. Coronavirus infections and immune responses. J Med Virol (2020) 92(4):424-32. doi: 10.1002/jmv.25685

71. Wang K, Chen W, Zhou Y, Lian J, Zhang Z, Du P, et al. SARS-CoV-2 invades host cells via a novel route: CD147-spike protein. bioRxiv [Preprint] (2020). doi: 10.1101/2020.03.14.988345

72. Chen IY, Moriyama M, Chang MF, Ichinohe T. Severe Acute Respiratory Syndrome Coronavirus Viroporin 3a Activates the NLRP3 Inflammasome. Front Microbiol (2019) 10:50. doi: 10.3389/fmicb.2019.00050

73. Shi CS, Nabar NR, Huang NN, Kehrl JH. SARS-Coronavirus Open Reading Frame-8b triggers intracellular stress pathways and activates NLRP3 inflammasomes. Cell Death Discov (2019) 5:101. doi: 10.1038/s41420-0190181-7

74. DeDiego ML, Nieto-Torres JL, Regla-Nava JA, Jimenez-Guardeno JM, Fernandez-Delgado R, Fett C, et al. Inhibition of NF-kappaB-mediated inflammation in severe acute respiratory syndrome coronavirus-infected mice increases survival. J Virol (2014) 88(2):913-24. doi: 10.1128/JVI.02576-13

75. Siu KL, Yuen KS, Castano-Rodriguez C, Ye ZW, Yeung ML, Fung SY, et al. Severe acute respiratory syndrome coronavirus ORF3a protein activates the NLRP3 inflammasome by promoting TRAF3-dependent ubiquitination of ASC. FASEB J (2019) 33(8):8865-77. doi: 10.1096/fj.201802418R

76. Kanzawa N, Nishigaki K, Hayashi T, Ishii Y, Furukawa S, Niiro A, et al. Augmentation of chemokine production by severe acute respiratory syndrome coronavirus $3 \mathrm{a} / \mathrm{X} 1$ and $7 \mathrm{a} / \mathrm{X} 4$ proteins through NF-kappaB activation. FEBS Lett (2006) 580(30):6807-12. doi: 10.1016/j.febslet.2006.11.046

77. Nieto-Torres JL, Verdia-Baguena C, Jimenez-Guardeno JM, Regla-Nava JA, Castano-Rodriguez C, Fernandez-Delgado R, et al. Severe acute respiratory syndrome coronavirus E protein transports calcium ions and activates the NLRP3 inflammasome. Virology (2015) 485:330-9. doi: 10.1016/j.virol.2015.08.010

78. Nieto-Torres JL, DeDiego ML, Verdia-Baguena C, Jimenez-Guardeno JM, Regla-Nava JA, Fernandez-Delgado R, et al. Severe acute respiratory syndrome coronavirus envelope protein ion channel activity promotes virus fitness and pathogenesis. PLoS Pathog (2014) 10(5):e1004077. doi: 10.1371/journal.ppat.1004077

79. Jimenez-Guardeno JM, Nieto-Torres JL, DeDiego ML, Regla-Nava JA, Fernandez-Delgado R, Castano-Rodriguez C, et al. The PDZ-binding motif of severe acute respiratory syndrome coronavirus envelope protein is a determinant of viral pathogenesis. PLoS Pathog (2014) 10(8):e1004320. doi: 10.1371/journal.ppat.1004320

80. Chang YS, Ko BH, Ju JC, Chang HH, Huang SH, Lin CW. SARS Unique Domain (SUD) of Severe Acute Respiratory SyndromeCoronavirus Induces NLRP3 Inflammasome-Dependent CXCL10-Mediated Pulmonary Inflammation. Int J Mol Sci (2020) 21(9):3179. doi: 10.3390/ijms21093179

81. He L, Ding Y, Zhang Q, Che X, He Y, Shen H, et al. Expression of elevated levels of pro-inflammatory cytokines in SARS-CoV-infected ACE2+ cells in SARS patients: relation to the acute lung injury and pathogenesis of SARS. J Pathol (2006) 210(3):288-97. doi: 10.1002/path.2067

82. Yue Y, Nabar NR, Shi CS, Kamenyeva O, Xiao X, Hwang IY, et al. SARSCoronavirus Open Reading Frame-3a drives multimodal necrotic cell death. Cell Death Dis (2018) 9(9):904. doi: 10.1038/s41419-018-0917-y

83. Issa E, Merhi G, Panossian B, Salloum T, Tokajian S. SARS-CoV-2 and ORF3a: Nonsynonymous Mutations, Functional Domains,and Viral Pathogenesis. mSystems (2020) 5(3):e00266-20. doi: 10.1128/mSystems.00266-20

84. Chan JF, Kok KH, Zhu Z, Chu H, To KK, Yuan S, et al. Genomic characterization of the 2019 novel human-pathogenic coronavirus isolated from a patient with atypical pneumonia after visiting Wuhan. Emerg Microbes Infect (2020) 9(1):221-36. doi: 10.1080/22221751.2020.1719902

85. Lu R, Zhao X, Li J, Niu P, Yang B, Wu H, et al. Genomic characterisation and epidemiology of 2019 novel coronavirus: implications for virus origins and receptor binding. Lancet (2020) 395(10224):565-74. doi: 10.1016/S01406736(20)30251-8

86. Li S, Jiang L, Li X, Lin F, Wang Y, Li B, et al. Clinical and pathological investigation of patients with severeCOVID-19. JCI Insight (2020) 5(12): e138070. doi: $10.1172 /$ jci.insight. 138070
87. Qin C, Zhou L, Hu Z, Zhang S, Yang S, Tao Y, et al. Dysregulation of immune response in patients with COVID-19 in Wuhan,China. Clin Infect Dis (2020) 71(15):762-8. doi: 10.1093/cid/ciaa248

88. Liu J, Li S, Liu J, Liang B, Wang X, Wang H, et al. Longitudinal characteristics of lymphocyte responses and cytokine profiles in the peripheral blood of SARS-CoV-2 infected patients. EBioMedicine (2020) 55:102763. doi: 10.1016/ j.ebiom.2020.102763

89. Wang F, Nie J, Wang H, Zhao Q, Xiong Y, Deng L, et al. Characteristics of Peripheral Lymphocyte Subset Alteration in COVID-19 Pneumonia. J Infect Dis (2020) 221(11):1762-9. doi: 10.1093/infdis/jiaa150

90. Ruan Q, Yang K, Wang W, Jiang L, Song J. Clinical predictors of mortality due to COVID-19 based on an analysis of data of 150 patients from Wuhan, China. Intensive Care Med (2020) 46(5):846-8. doi: 10.1007/s00134-020-05991-x

91. Yang Y, Shen C, Li J, Yuan J, Wei J, Huang F, et al. Plasma IP-10 and MCP-3 levels are highly associated with diseaseseverity and predict the progression of COVID-19. J Allergy ClinImmunol (2020) 146(1):119-27. doi: 10.1016/ j.jaci.2020.04.027

92. Varga Z, Flammer AJ, Steiger P, Haberecker M, Andermatt R, Zinkernagel AS, et al. Endothelial cell infection and endotheliitis in COVID-19. Lancet (2020) 395(10234):1417-8. doi: 10.1016/S0140-6736(20)30937-5

93. Deftereos SG, Giannopoulos G, Vrachatis DA, Siasos GD, Giotaki SG, Gargalianos P, et al. Effect of Colchicine vs Standard Care on Cardiac and Inflammatory Biomarkers and Clinical Outcomes in Patients Hospitalized With Coronavirus Disease 2019: The GRECCO-19 Randomized Clinical Trial. JAMA Netw Open (2020) 3(6):e2013136. doi: 10.1001/jamanetworkopen.2020.13136

94. Montealegre-Gomez G, Garavito E, Gomez-Lopez A, Rojas-Villarraga A, ParraMedina R. [Colchicine: a potential therapeutic tool against COVID-19. Experience of 5 patients]. Reumatol Clin (2020). doi: 10.1016/j.reuma.2020.05.001

95. Della-Torre E, Della-Torre F, Kusanovic M, Scotti R, Ramirez GA, Dagna L, et al. Treating COVID-19 with colchicine in community healthcare setting. Clin Immunol (2020) 217:108490. doi: 10.1016/j.clim.2020.108490

96. Ito M, Shichita T, Okada M, Komine R, Noguchi Y, Yoshimura A, et al. Bruton's tyrosine kinase is essential for NLRP3 inflammasome activation and contributes to ischaemic brain injury. Nat Commun (2015) 6:7360. doi: $10.1038 /$ ncomms 8360

97. Purvis GSD, Collino M, Aranda-Tavio H, Chiazza F, O’Riordan CE, Zeboudj $\mathrm{L}$, et al. Inhibition of Bruton's tyrosine kinase regulates macrophageNFkappaB and NLRP3 inflammasome activation in metabolic inflammation. $\mathrm{Br}$ JPharmacol (2020) 177(19):4416-32. doi: 10.1111/bph.15182

98. Scarsi M, Piantoni S, Colombo E, Airo P, Richini D, Miclini M, et al. Association between treatment with colchicine and improved survivalin a single-centre cohort of adult hospitalised patients with COVID-19 pneumonia and acuterespiratory distress syndrome. Ann Rheum Dis (2020)79:1286-9. doi: 10.1136/annrheumdis-2020-217712

99. Gautret P, Lagier JC, Parola P, Hoang VT, Meddeb L, Mailhe M, et al. Hydroxychloroquine and azithromycin as a treatment of COVID-19: results of an open-label non-randomized clinical trial. Int J Antimicrob Agents (2020) 56(1):105949. doi: 10.1016/j.ijantimicag.2020.105949

100. Fujita Y, Matsuoka N, Temmoku J, Furuya MY, Asano T, Sato S, et al. Hydroxychloroquine inhibits IL-1beta production from amyloid-stimulated human neutrophils. Arthritis Res Ther (2019) 21(1):250. doi: 10.1186/s13075-0192040-6

101. Lucchesi A, Silimbani P, Musuraca G, Cerchione C, Martinelli G, Di Carlo P, et al. Clinical and biological data on the use of hydroxychloroquine against SARS-CoV2 could support the role of the NLRP3 inflammasome in the pathogenesis of respiratory disease. J Med Virol (2020). doi: 10.1002/jmv.26217

102. Cavalli G, De Luca G, Campochiaro C, Della-Torre E, Ripa M, Canetti D, et al. Interleukin-1 blockade with high-dose anakinra in patients with COVID-19, acute respiratory distress syndrome, and hyperinflammation: a retrospective cohort study. Lancet Rheumatol (2020) 2(6):e325-e31. doi: 10.1016/S2665-9913(20)30127-2

103. Day JW, Fox TA, Halsey R, Carpenter B, Kottaridis PD. Interleukin-1 blockade with anakinra in acute leukaemia patientswith severe COVID-19 pneumonia appears safe and may result in clinical improvement. $\mathrm{Br} \mathrm{J}$ Haematol. (2020) 190(2):e80-e83. doi: 10.1111/bjh.16873

104. Xu X, Han M, Li T, Sun W, Wang D, Fu B, et al. Effective treatment of severe COVID-19 patients with tocilizumab. Proc Natl Acad Sci U S A (2020) 117 (20):10970-5. doi: 10.1073/pnas.2005615117 
105. Toniati P, Piva S, Cattalini M, Garrafa E, Regola F, Castelli F, et al. Tocilizumab for the treatment of severe COVID-19 pneumonia with hyperinflammatory syndrome and acute respiratory failure: A single center study of 100 patients in Brescia, Italy. Autoimmun Rev (2020) 19(7):102568. doi: 10.1016/j.autrev.2020.102568

106. Capra R, De Rossi N, Mattioli F, Romanelli G, Scarpazza C, Sormani MP, et al. Impact of low dose tocilizumab on mortality rate in patients with COVID-19 related pneumonia. Eur J Intern Med (2020) 76:31-5. doi: 10.1016/j.ejim.2020.05.009

107. Rathkey JK, Zhao J, Liu Z, Chen Y, Yang J, Kondolf HC, et al. Chemical disruption of the pyroptotic pore-forming protein gasderminD inhibits inflammatory cell death and sepsis. Sci Immunol (2018) 3(26):eaat2738. doi: 10.1126/sciimmunol.aat 2738

108. Hu JJ, Liu X, Xia S, Zhang Z, Zhang Y, Zhao J, et al. FDA-approved disulfiram inhibits pyroptosis by blocking gasdermin D pore formation. Nat Immunol (2020) 21(7):736-45. doi: 10.1038/s41590-020-0669-6

109. Lee HM, Kim JJ, Kim HJ, Shong M, Ku BJ, Jo EK. Upregulated NLRP3 inflammasome activation in patients with type 2 diabetes. Diabetes (2013) 62 (1):194-204. doi: 10.2337/db12-0420

110. Pereira CA, Carlos D, Ferreira NS, Silva JF, Zanotto CZ, Zamboni DS, et al. Mitochondrial DNA Promotes NLRP3 Inflammasome Activation and Contributes to Endothelial Dysfunction and Inflammation in Type 1 Diabetes. Front Physiol (2019) 10:1557. doi: 10.3389/fphys.2019.01557

111. Sun HJ, Ren XS, Xiong XQ, Chen YZ, Zhao MX, Wang JJ, et al. NLRP3 inflammasome activation contributes to VSMC phenotypic transformation and proliferation in hypertension. Cell Death Dis (2017) 8(10):e3074. doi: $10.1038 /$ cddis.2017.470

112. Guo DH, Yamamoto M, Hernandez CM, Khodadadi H, Baban B, Stranahan AM. Visceral adipose NLRP3 impairs cognition in obesity via IL-1R1 on CX3CR1+ cells. J Clin Invest (2020) 130(4):1961-76. doi: 10.1172/JCI126078

113. Canadas-Lozano D, Marin-Aguilar F, Castejon-Vega B, Ryffel B, NavarroPando JM, Ruiz-Cabello J, et al. Blockade of the NLRP3 inflammasome improves metabolic health and lifespan in obese mice. Geroscience (2020) 42(2):715-25. doi: 10.1007/s11357-019-00151-6

114. Hernandez-Garduno E. Obesity is the comorbidity more strongly associated for Covid-19 inMexico. A case-control study. Obes Res Clin Pract (2020) 14 (4):375-9. doi: 10.1016/j.orcp.2020.06.001

115. Deng Y, Liu W, Liu K, Fang YY, Shang J, Zhou L, et al. Clinical characteristics of fatal and recovered cases of coronavirus disease 2019 in Wuhan, China: a retrospective study. Chin Med J (Engl) (2020) 133(11):1261-7. doi: 10.1097/ CM9.0000000000000824

116. Grasselli G, Zangrillo A, Zanella A, Antonelli M, Cabrini L, Castelli A, et al. Baseline Characteristics and Outcomes of 1591 Patients Infected WithSARSCoV-2 Admitted to ICUs of the Lombardy Region, Italy. JAMA (2020) 323 (16):1574-81. doi: 10.1001/jama.2020.5394

117. Cummings MJ, Baldwin MR, Abrams D, Jacobson SD, Meyer BJ, Balough EM, et al. Epidemiology, clinical course, and outcomes of critically ill adults with COVID-19 in New York City: a prospective cohort study. Lancet (2020) 395(10239):1763-70. doi: 10.1016/S0140-6736(20)31189-2

118. Kass DA, Duggal P, Cingolani O. Obesity could shift severe COVID-19 disease to younger ages. Lancet (2020) 395(10236):1544-5. doi: 10.1016/ S0140-6736(20)31024-2

119. Klang E, Kassim G, Soffer S, Freeman R, Levin MA, Reich DL. Morbid Obesity as an Independent Risk Factor for COVID-19 Mortalityin Hospitalized Patients Younger than 50. Obesity (Silver Spring) (2020) 28 (9):1595-9. doi: 10.1002/oby.22913

120. Bhatraju PK, Ghassemieh BJ, Nichols M, Kim R, Jerome KR, Nalla AK, et al. Covid-19 in Critically Ill Patients in the Seattle Region - Case Series. N Engl J Med (2020) 382(21):2012-22. doi: 10.1056/NEJMoa2004500

121. Petrilli CM, Jones SA, Yang J, Rajagopalan H, O’Donnell L, Chernyak Y, et al. Factors associated with hospital admission and critical illness among 5279 people with coronavirus disease 2019 in New York City: prospective cohort study. BMJ (2020) 369:m1966. doi: 10.1136/bmj.m1966

122. Cai Q, Chen F, Wang T, Luo F, Liu X, Wu Q, et al. Obesity and COVID-19 Severity in a Designated Hospital in Shenzhen, China. Diabetes Care (2020) 43(7):1392-8. doi: 10.2337/dc20-0576
123. Zhang F, Xiong Y, Wei Y, Hu Y, Wang F, Li G, et al. Obesity predisposes to the risk of higher mortality in youngCOVID-19 patients. J Med Virol (2020) 92(11):2536-42. doi: 10.1002/jmv.26039

124. Valente-Acosta B, Hoyo-Ulloa I, Espinosa-Aguilar L, Mendoza-Aguilar R, Garcia-Guerrero J, Ontañon-Zurita D, et al. COVID-19 severe pneumonia in Mexico City - First experience in a Mexican hospital. medRxiv [Preprint] (2020). doi: 10.1101/2020.04.26.20080796

125. Simonnet A, Chetboun M, Poissy J, Raverdy V, Noulette J, Duhamel A, et al. High Prevalence of Obesity in Severe Acute Respiratory Syndrome Coronavirus-2 (SARS-CoV-2) Requiring Invasive Mechanical Ventilation. Obesity (Silver Spring) (2020) 28(7):1195-9. doi: 10.1002/oby.22831

126. Kassir R. Risk of COVID-19 for patients with obesity. Obes Rev (2020) 21(6): e13034. doi: 10.1111/obr.13034

127. Jia X, Yin C, Lu S, Chen Y, Liu Q, Bai J, et al. Two Things About COVID-19 Might Need Attention. Preprints (2020) 2020020315. doi: 10.20944/ preprints202002.0315.v1

128. Jose RJ, Manuel A. Does Coronavirus Disease 2019 Disprove the Obesity Paradox in Acute Respiratory Distress Syndrome? Obesity (Silver Spring) (2020) 28(6):1007. doi: 10.1002/oby.22835

129. Petrakis D, Margina D, Tsarouhas K, Tekos F, Stan M, Nikitovic D, et al. Obesity a risk factor for increased COVID19 prevalence, severity and lethality (Review). Mol Med Rep (2020) 22(1):9-19. doi: 10.3892/mmr.2020.11127

130. Wang HE, Griffin R, Judd S, Shapiro NI, Safford MM. Obesity and risk of sepsis: a population-based cohort study. Obesity (Silver Spring) (2013) 21 (12):E762-9. doi: 10.1002/oby.20468

131. Yeoh AJ, Pedley A, Rosenquist KJ, Hoffmann U, Fox CS. The Association Between Subcutaneous Fat Density and the Propensity to Store Fat Viscerally. J Clin Endocrinol Metab (2015) 100(8):E1056-64. doi: 10.1210/ jc. 2014-4032

132. Carbone S, Lavie CJ, Arena R. Obesity and Heart Failure: Focus on the Obesity Paradox. Mayo Clin Proc (2017) 92(2):266-79. doi: 10.1016/j.mayocp.2016.11.001

133. Kruglikov IL, Scherer PE. The Role of Adipocytes and Adipocyte-Like Cells in the Severity of COVID-19 Infections. Obesity (Silver Spring) (2020) 28 (7):1187-90. doi: 10.1002/oby.22856

134. Wildman RP, Muntner P, Reynolds K, McGinn AP, Rajpathak S, Wylie-Rosett J, et al. The obese without cardiometabolic risk factor clustering and the normal weight with cardiometabolic risk factor clustering: prevalence and correlates of 2 phenotypes among the US population (NHANES 1999-2004). Arch Intern Med (2008) 168(15):1617-24. doi: 10.1001/archinte.168.15.1617

135. Donini LM, Pinto A, Giusti AM, Lenzi A, Poggiogalle E. Obesity or BMI Paradox? Beneath the Tip of the Iceberg. Front Nutr (2020) 7:53. doi: $10.3389 /$ fnut. 2020.00053

136. Esser N, L'Homme L, De Roover A, Kohnen L, Scheen AJ, Moutschen M, et al. Obesity phenotype is related to NLRP3 inflammasome activity and immunological profile of visceral adipose tissue. Diabetologia (2013) 56 (11):2487-97. doi: 10.1007/s00125-013-3023-9

137. Christ A, Gunther P, Lauterbach MAR, Duewell P, Biswas D, Pelka K, et al. Western Diet Triggers NLRP3-Dependent Innate Immune Reprogramming. Cell (2018) 172(1-2):162-75.e14. doi: 10.1016/j.cell.2017.12.013

138. Bekkering S, Saner C, Riksen NP, Netea MG, Sabin MA, Saffery R, et al. Trained Immunity: Linking Obesity and Cardiovascular Disease across the Life-Course? Trends Endocrinol Metab (2020) 31(5):378-89. doi: 10.1016/ j.tem.2020.01.008

Conflict of Interest: The authors declare that the research was conducted in the absence of any commercial or financial relationships that could be construed as a potential conflict of interest.

Copyright (C) 2020 López-Reyes, Martinez-Armenta, Espinosa-Velázquez, Vázquez-Cárdenas, Cruz-Ramos, Palacios-Gonzalez, Gomez-Quiroz and Martinez-Nava. This is an open-access article distributed under the terms of the Creative Commons Attribution License (CC BY). The use, distribution or reproduction in other forums is permitted, provided the original author(s) and the copyright owner(s) are credited and that the original publication in this journal is cited, in accordance with accepted academic practice. No use, distribution or reproduction is permitted which does not comply with these terms. 